\title{
Comparison and Finite Element Analysis of Steel or Synthetic Fiber Reinforced Precast, Prestressed Beams
}

\author{
Gábor Kovács ${ }^{1}$, Károly Péter Juhász ${ }^{2}$ and Botond Madaras ${ }^{3}$ \\ 1. ASA Construction Ltd., Budapest H-1136, Hungary \\ 2. Department of Mechanics, Materials and Structures, Budapest University of Technology and Economist, Budapest H-1135, Hungary \\ 3. ÉMI-TÜV SÜD Ltd., Budapest H-1043, Hungary
}

\begin{abstract}
Usage of fiber reinforced concrete to replace shear reinforcement has become more common in the precast industry in recent years. In some cases, the use of steel fibers could be problematic because of corrosion, hence, synthetic material could be a suitable alternative material solution. Thus, it would appear logical to undertake a comparison of these fibers' load bearing capacity to determine suitability in each case. In this paper, the bending and the shear tests of four large-scale and prestressed beams made of steel or synthetic fiber reinforced concrete without stirrups are presented. The post-cracking residual tensile strength diagram of the fibers, according to RILEM (International Union of Laboratories and Experts in Construction Materials, Systems and Structures) TC162, is given and the experimental behavior of the fiber solutions is compared. The modified fracture energy method is used to define an advanced material model for the fiber reinforced concrete in the finite element analysis. The numerical calculations and the test results are compared in terms of crack propagation and the loading-deflection process. As a consequence, both steel and synthetic fibers seem to be good alternatives to replace the stirrups. However, the behavior of each fiber is not the same. The numerical calculation provided a good approximation for the real scale tests.
\end{abstract}

Key words: Synthetic fiber, steel fiber, prestress, precast, finite element analysis.

\section{Introduction}

Over the last 40 years, FRC (fiber reinforced concrete) was mostly used in fully supported slab structures, such as industrial floors, pavements, roads, track slabs or shotcrete [1]. More recently, considerable development has been experienced in the materials of the fibers and in the calculation methods used to justify their behavior. With FEA (finite element analysis), based on the use of the increased fracture energy, more accurate results can be reached. By using fibers in the concrete, conventional stirrups can be substituted, and thus, the material and labor cost of the light reinforcement can be saved [2]. This opens up new FRC applications, especially in the prefabricated industry, e.g., grandstand elements of a stadium [3].

Corresponding author: Gábor Kovács, M.Sc., engineer, research field: fiber reinforced concrete. E-mail: nazra8@gmail.com.
To replace reinforcement in traditional concrete, two common solutions are given on the market: steel and synthetic macro fibers. In this paper, we used widespread and high quality fibers, which were selected partly in our previous studies [4-6]. This paper focuses on the effect of these materials in traditional concrete and it compares their behavior in precast and prestressed beams with FEA calculations.

\section{Materials and Beams}

Four large-scale, prismatic, prestressed, $19.0 \mathrm{~m}$ long, T-shaped beams were produced. Two beams were made of steel fibers (length: $60 \mathrm{~mm}$; diameter: $0.75 \mathrm{~mm}$; tensile strength: $1,225 \mathrm{~N} / \mathrm{mm}^{2}$; dosage: $30.0 \mathrm{~kg} / \mathrm{m}^{3}$ ) and two beams were made of macro synthetic fibers (length: $48 \mathrm{~mm}$; diameter: $1.3 \times 0.5 \mathrm{~mm}$; tensile strength: $640 \mathrm{~N} / \mathrm{mm}^{2}$; dosage: $5.0 \mathrm{~kg} / \mathrm{m}^{3}$ ).

For testing of the material properties, the mean 
residual tensile strength of the plain and the fiber reinforced concrete was measured on three prisms according to RILEM TC162 [7] as can be seen in Fig. 1. It shows the rigid behavior of the plain concrete and it proves that both fibers have reasonable resistance after cracking.

In case of the synthetic fiber, the diagram starts with a remarkable softening phase $(0.0 \sim 0.5 \mathrm{~mm})$ and ends with a rather constant section after a moderate increase $(0.5 \sim 4.0 \mathrm{~mm})$. The opposite is valid for the steel fiber, which always gives higher values than the synthetic one. It can be characterized with an initial hardening section $(0.0 \sim 1.5 \mathrm{~mm})$ and with a softening behavior at the high CMOD (crack mouth opening displacement) values $(1.5 \sim 4.0 \mathrm{~mm})$.

The cross-section and the reinforcement details of the beams can be seen in Fig. 2. The height was $90 \mathrm{~cm}$, the width of the flange was $50 \mathrm{~cm}$ and the web thickness was $14 \mathrm{~cm}$.

Twelve prestressing strands (diameter: $12.5 \mathrm{~mm}$, cross-sectional area: $0.93 \mathrm{~cm}^{2}$; initial prestress: $950 \mathrm{~N} / \mathrm{mm}^{2}$; material: Y1860S7-F1-C1) were placed in six rows with $4 \mathrm{~cm}$ axis distance. Four prestressing strands (diameter: $9.3 \mathrm{~mm}$; cross-sectional area: $0.52 \mathrm{~cm}^{2}$; initial prestress: $865 \mathrm{~N} / \mathrm{mm}^{2}$; material: Y1860S7-F1-C1) were placed in one line in the flange. The yield strength of the strands is $1,640 \mathrm{~N} / \mathrm{mm}^{2}$.

The calculated and the minimum shear reinforcement were substituted with fibers. This solution is not covered by the recent design standard, the Eurocode 2 [8].

Only six quasi-stirrups (diameter: $8 \mathrm{~mm}$, material: B500B) with $45 \sim 50 \mathrm{~cm}$ height were placed in $1.0 \mathrm{~m}$ from the beam end to avoid spalling cracks. After the prestressing force had been released, $10-\mathrm{cm} \sim 40-\mathrm{cm}$ long cracks with $0.05-\mathrm{mm} \sim 0.3-\mathrm{mm}$ width appeared above the reinforcement and $15-\mathrm{cm} \sim 45-\mathrm{cm}$ long cracks with $0.1-\mathrm{mm}$ width appeared between the web and the flange. The crack width did not change during the tests and they did not influence the load bearing capacity of the beams.

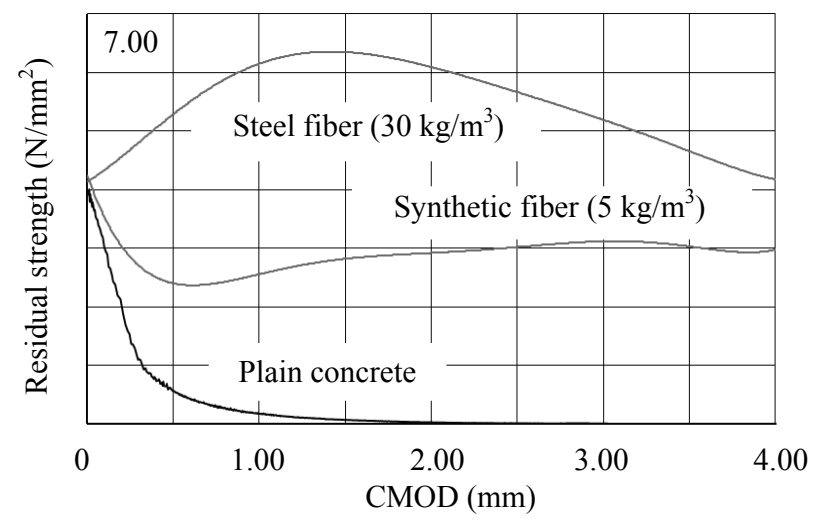

Fig. 1 Residual strength-CMOD diagram.

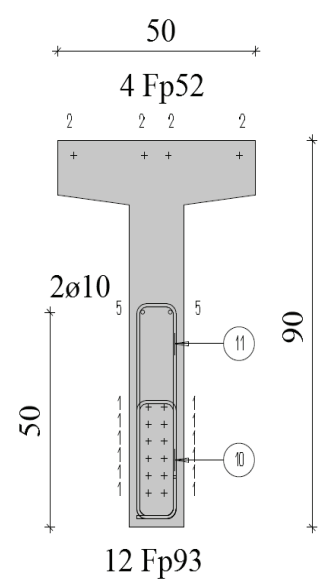

(a)

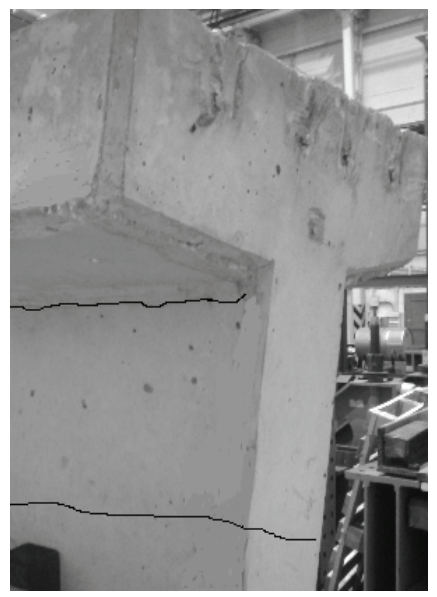

(b)
Fig. 2 Test beam: (a) cross-section; (b) reinforcement details and initial cracks (units in $\mathrm{cm}$ ).

The concrete class was $\mathrm{C} 50 / 60-\mathrm{XC} 1-16$. The homogeneity of the strength was proven by the measurement of the Schmidt hammer.

\section{Laboratory Tests}

To observe the general behavior of fiber reinforced concrete in long-span prestressed beams and to compare their load bearing capacity, bending and shear tests were performed under laboratory conditions according to the national standard (Fig. 3) [9].

In the former case, a modified four-point test was used to model the built-in loading situation of the girders: two action forces were located in each one-third point of the span and they loaded the precast beam through simply supported steel beams at each one-fifth point. 


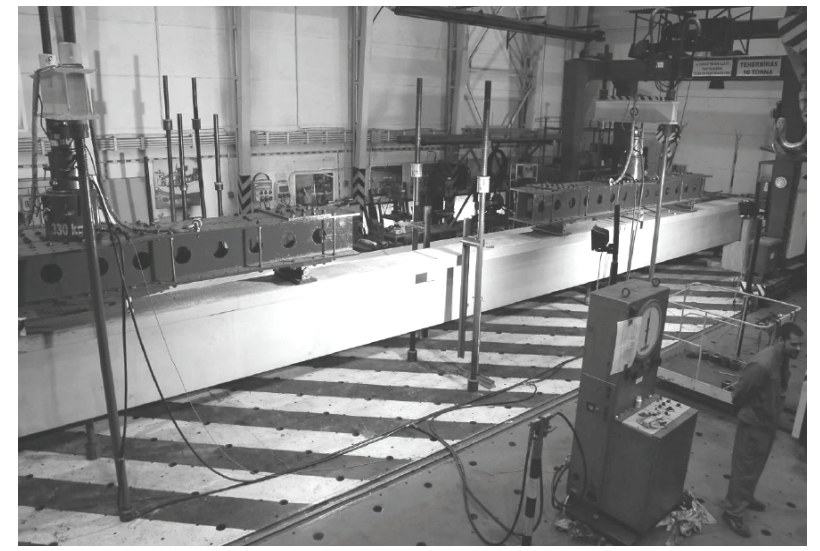

(a)

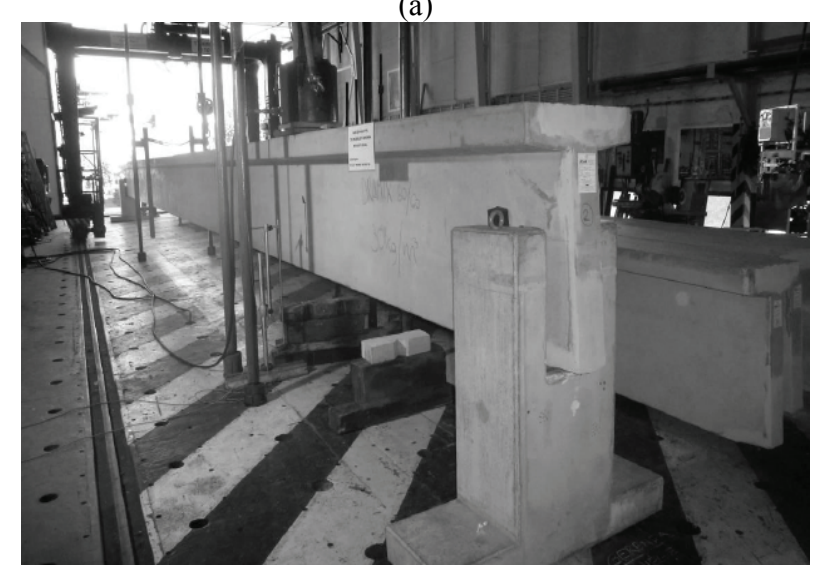

(b)

Fig. 3 Test setup: (a) bending; (b) shear.

Force and deflection in the middle of the span were recorded in 15 load-steps, and 5 10 min standing time was used between them. The crack propagation process was photographed and summarized in tables.

It was decided after reaching $130 \%$ of the bending resistance's design value which was calculated according to recent standard, Eurocode 2 [8] without taking the effect of the fibers into consideration - the loading was stopped, without experiencing the break-off failure to remain the beam-end uncracked for the shear tests. Therefore, a crack with $1.0 \mathrm{~mm}$ width was considered as failure.

In the shear test only one action force was located nearly $2.5 h$ ( $h$ is the height of the beam) distance from the beam end and it was increased until failure.

\section{Test Results}

Beams made of steel or synthetic fiber reinforced concrete showed similar load bearing capacity and

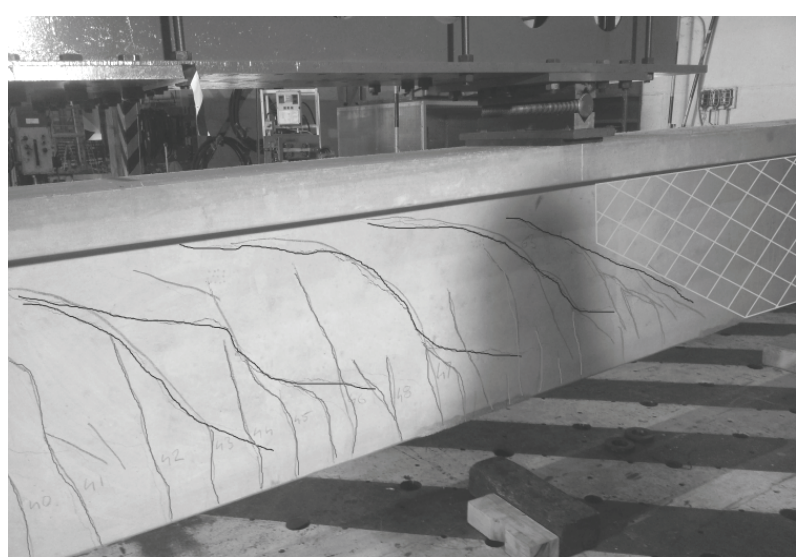

(a)

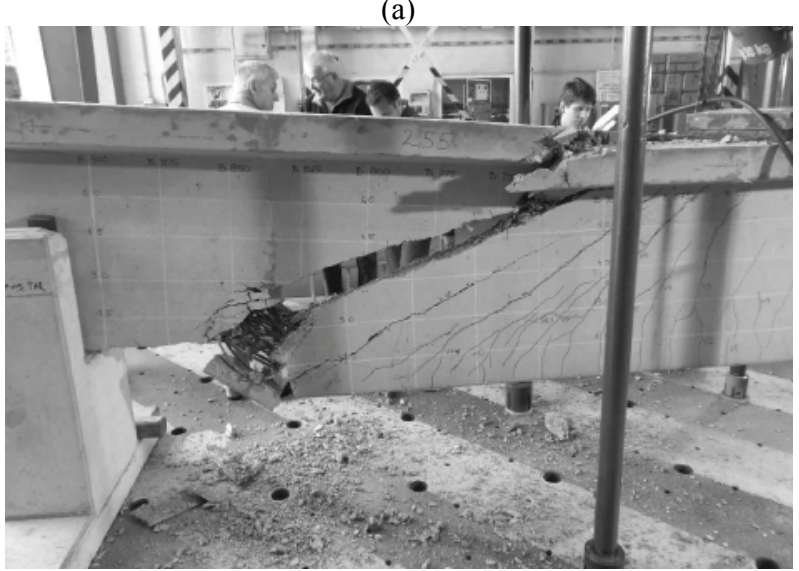

(b)

Fig. 4 Crack pattern after: (a) bending; (b) shear tests.

deflection, but there were differences in the deformation process.

During the bending tests, the beam end remained uncracked, but the middle part of the beam between the outside loading machines was frequently cracked (Fig. 4). The propagation started from the soffit and while the load was increased, cracks reached the flange and their width become even higher. The width of $1.0 \mathrm{~mm}$ was observed at $120 \%$ of the bending resistance's design value.

In the case of synthetic fibers, the crack propagation process started earlier at a lower bending moment was faster and cracks were located closer to each other. In the seventh load step, diagonal cracks appeared at the outside loads. In the case of steel fibers, the same was observed only in tenth. After two loading levels, their width was the same as pure bending cracks'. The inclination of the newer cracks was lower. In the last loading level, they reached 1.0-mm width. Failure was 
observed at the shear-bending zone with an obvious prognostic in both cases.

The initial tangential of both solutions is similar (Fig. 5). After the first crack appears, the stiffness of the steel fiber reinforced beams become higher, but in the end of the deflection process, the stiffnesses are again equalized. The plasticity at the characteristic load level is remarkably higher in case of synthetic fibers, which is visualized by the significant different areas of hysteresis loops in the loading-unloading-reloading section.

In the shear tests, first cracks appeared at $115 \%$ of the resistance design value, which was calculated without taking the effect of the fibers into consideration. The $1.0-\mathrm{mm}$ crack width was observed at $200 \%$, while the collapse was experienced at $230 \%$. All the cracks went from the support to the loading machine (Fig. 4). The inclination of the firstly appeared cracks was $35^{\circ} \sim 45^{\circ}$, and in the case of the newer cracks, it was $18^{\circ}$. Failure was ductile in both cases.

\section{Finite Element Analysis}

\subsection{Material Model}

The effect of the fibers in the concrete was analyzed in the grandstand elements [3]. The same method was used in this research.

Three point bending tests were performed on $150 \mathrm{~mm} \times 150 \mathrm{~mm}$ and $550-\mathrm{mm}$ long beams, according to RILEM TC162 [7], and then inverse analysis was carried out. The fracture energy, obtained from the fiber performance, was determined for the different fiber dosages. It was made by the virtual beam test, which involves the modeling of the real beam in the finite element software and the yielding of the same load-CMOD diagram that occurred in physical tests.

The inverse analysis was iterated until the area, under the numerical load-CMOD diagrams, matched those in the physical material tests.

Modified fracture energy is a new and simple method to model the behavior of FRC in tension and bending [10]. The main idea is to use the concrete fracture energy $\left(G_{f}\right)$ as an initial value and then increase it with the additional fracture energy $\left(G_{f f}\right)$ gained from the post-crack FRC performance. The residual tensile stress was modeled with a constant value $\left(f_{f}\right)$. The stress-crack width diagram was limited to $w_{f}=3 \mathrm{~mm}$ due to engineering considerations (Fig. 6). However, it never reached such a high value, not even in the ULS (ultimate limit state).

The concrete was modeled as a 3D (three dimensional) brick element with a material model that consists of a combined fracture-plastic failure surface [11]. Tension is handled herein by a fracture model, based on the classical orthotropic smeared crack formulation and the crack band approach. It employs the Rankine cube failure criterion, and it can be used as a rotated or a fixed crack model. The plasticity model uses the William-Menétrey failure surface for the concrete in compression [12]. The aggregate

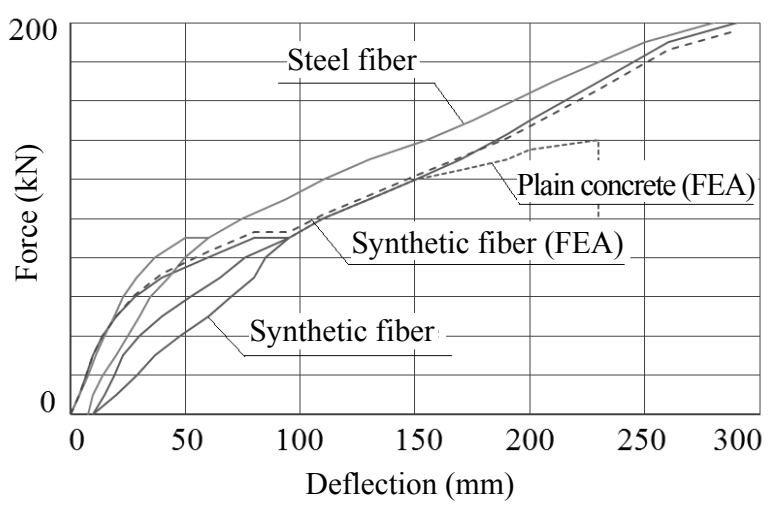

Fig. 5 Force-deflection diagram of the beams.

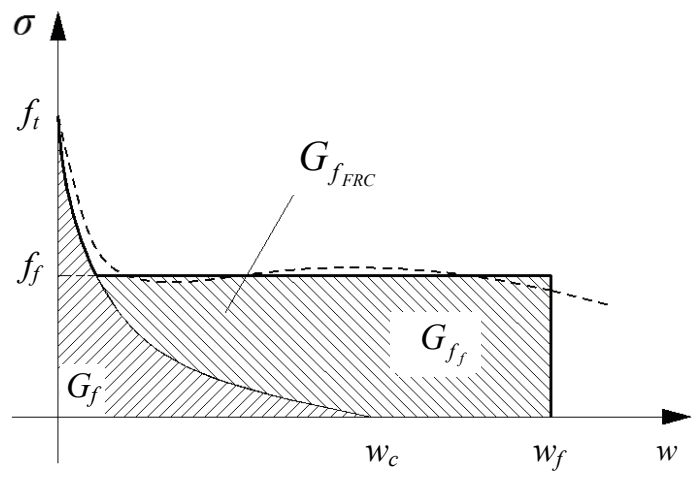

Fig. 6 Fracture energy of the concrete and FRC. 
interlock change is taken into account by a reduction of the shear modulus with growing strain along the crack plane, according to the law derived by Kolmar [13].

The concrete has a stress-strain diagram according to Eurocode 2 [8]. The crack width was calculated from the stress-crack width diagram. It is determined by the inverse analysis with the help of the characteristic length, which is a function of the element size and the angle of the crack within the element [14]. The main advantage of this advanced material model is that it is the only one which can represent the cracks in the quasi-brittle material realistically.

Steel rebars were modeled as discrete link elements with uniaxial and ideal elastic-plastic stress-strain material properties. The rebar's link element was connected to each crossed concrete brick element.

\subsection{Numerical Model}

The beam was symmetrical to the middle point of the span, so only half of the beam was sufficient to model with symmetrical support conditions on the specified plane. It helps us to define the boundary conditions and it makes the calculation faster.

The loading head was modeled with roll free nodes, and the load was deflection controlled. Consequently, the fall backs in the load-deflection diagrams could be modeled. The loading consists of two intervals: (1) the prestress of the steel bars; (2) the displacement incremented loading.

\subsection{Comparison of the Numerical and Test Results}

The added fracture energy of the steel fiber is mostly equal to the synthetic fiber's. Both material models are verified and appropriate in terms of the finite element modeling. This is highlighted in the load-deflection diagram of the test: The characteristic of both curves are very similar and they run very close to each other.

The load-deflection diagram of the numerical analysis shows close correlation with the test result (Fig. 5).

The crack propagation, according to the FEA, also shows reasonable similarities with the visually observed crack pattern. The spalling cracks, which were observed after the release of the prestressing force, are also present in the calculation.

To present the effect of the fibers, the FRC's material model is changed to plain concrete by reducing the added fracture energy $\left(G_{f f}\right)$ to 0 . The load bearing capacity decreases approximately $50 \%$ in this case (Fig. 5), as the crack localization is faster. With the help of the FEA, more conditions can be tested.

In case of both the steel and the synthetic fibers, the effect of creep is not well clarified or generally accepted. It is proposed, therefore, to measure the crack width at the SLS (serviceability limit state), and it predicts the possible creep in long-term loading. Moreover, if there are no cracks in the SLS, the fiber could be said to function only in ULS, which would exclude the creep problems. Under conventional circumstances, shear failure occurs only in ULS, while, consequently, it might be stated that the use of fiber to increase shear capacity could be approved in the long term.

\section{Conclusions}

Advanced statistical analysis cannot be performed due to the limited number of the tests, but the structural behavior of the FRC beams was clear. There was no difference between steel and synthetic fiber reinforcing in their load bearing capacity, although the characteristic of the load-deflection curve was different. Failure was ductile with obvious prognostic in both cases.

After the first crack has appeared, the stiffness of the steel fiber reinforced concrete became higher than the synthetic fiber's, but in the end of the deflection process, stiffnesses were again equalized. The plasticity in the characteristic load level was remarkably higher in case of the synthetic fibers. 
The modified fracture energy, whose parameters' were calculated by the inverse analysis of three point bending tests, provides a suitable method to model the effect of fibers. The advanced concrete material model, which includes the combined failure surface and the aggregate interlock effect, shows good correlation with the real scale tests both in the load-deflection process and in the crack propagation.

The existence of horizontal spalling cracks on the beam end was predicted by the verified FEA. The load bearing capacity of the FRC solution is approximately $50 \%$ higher compared to plain concrete, according to the numerical calculations. According to our research, the design of steel or macro-synthetic FRC for shear resistance is considered to be substantiated.

\section{Acknowledgments}

The authors would like to express their thanks to the laboratory of ÉMI TÜV SÜD Ltd., where the long-span beam tests were performed in an exceptionally professional way.

\section{References}

[1] Balaguru, P. N., and Shah, S. P. 1992. Fiber-Reinforced Cement Composites. USA: McGraw-Hill Inc.

[2] Kovács, G., Bódi, I., and Karkiss, B. 2011. "Analysis of Prefabricated and Prestressed Edge Beams Produced by Slipformer Technology with SFRC." fib Symposium Prague 2: 847-50.

[3] Kovács, G., and Juhász, K. P. 2013. "Precast, Prestressed Grandstand of PFRC in Stadium, Hungary." Presented at Central European Congress on Concrete Engineering in Wroclaw 2013, Wroclaw.

[4] Juhász, K. P. 2013. "The Observation of Samples Made of Micro and Macro Synthetic Fiber Reinforced Concrete." Épités-Épitészettudomány 42 (1-2): 57-72. (in Hungarian)

[5] István, S., and Péter, J. K. 2012. "The Big Crack." Budapest University of Technology and Economics. Accessed April 4, 2015. http://szt.bme.hu/files/ juhasz/labor/BME_The_big_crack_2012.pdf.

[6] István, S. 2012. "The Big Crack 2-European Fibres." Budapest University of Technology and Economics. Accessed April 4, 2015. http://szt.bme.hu/files/juhasz/ labor/European\%20fibers_ENG_email.pdf.

[7] Vandewalle, C. L. 2003. "RILEM TC 162-TDF: Test and Design Methods for Steel Fibre Reinforced Concrete, $\sigma-\varepsilon$-Design Method." Materials and Structures 36: 560-7.

[8] CEN (European Committee for Standardization). 2004. Eurocode 2, EN 1992, 2004. European Code for Design of Concrete Structure. CEN. Accessed April 4, 2015. http://eurocodes.jrc.ec.europa.eu/.

[9] Hugnarian Standards Institution. 1988. MSZ 16030/1-1998, Precast Concrete Elements. Quality Control. Hugnarian Standards Institution.

[10] Péter, J. K. 2013. "Modified Fracture Energy Method for Fibre Reinforced Concrete." In Proceedings of Fibre Concrete 2013: Technology, Design, Application, 89-90.

[11] Cervenka, J., and Papanikolaou, V. K. 2008. "Three Dimensional Combined Fracture-Plastic Material Model for Concrete." International Journal of Plasticity 24: 2192-220

[12] Menétrey, P., and William, K. J. 1995. "Triaxial Failure Criterion for Concrete and Its Generalization." $A C I$ (American Concrete Institute) Structural Journal 92 (3): 311-8.

[13] Kolmar, W. 1986. "Description of the Force Transmission in Cracks by Using Non-linear Finite Element Analysis for Reinforced Concrete." Dissertation, Technische Universität Darmstadt. (in German)

[14] Bazant, Z. P., and Oh, B. H. 1984. "Crack Band Theory for Fracture of Concrete." Materials and Structures 16: $155-77$. 